\title{
HACIA LAS COMUNIDADES VIRTUALES DE APRENDIZAJE, APRENDER PARA APROPIARSE DE LOS NUEVOS MEDIOS DIGITALES.
}

Resumen: Se presentan los resultados de un análisis de los procesos de formación, considerando las posibilidades de los entornos virtuales para facilitar u obstaculizar la colaboración en Red, y por ende la construcción de comunidades de práctica, con la finalidad de avanzar hacia la construcción de comunidades de aprendizaje, basadas en la colaboración a distancia haciendo uso de un entorno de teleformación. lo anterior para de evaluar de qué forma esos sistemas de gestión de los aprendizajes en Red (LMS) incorporan elementos de diseño virtual para la metodología que se desea incorporar en los procesos de evaluación cualitativa y cuantitativa, específicamente los espacios virtuales para el trabajo colaborativo y las herramientas de comunicación como son los foros virtuales.

Palabras clave: Comunidades de Práctica, Tutoría en Línea, ambientes virtuales de aprendizaje.

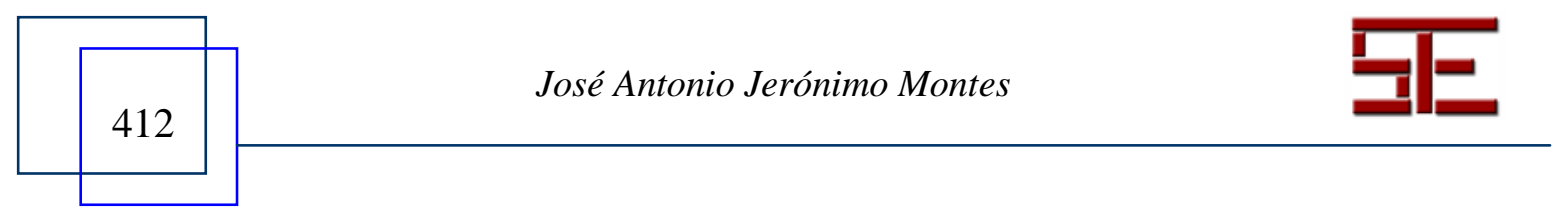




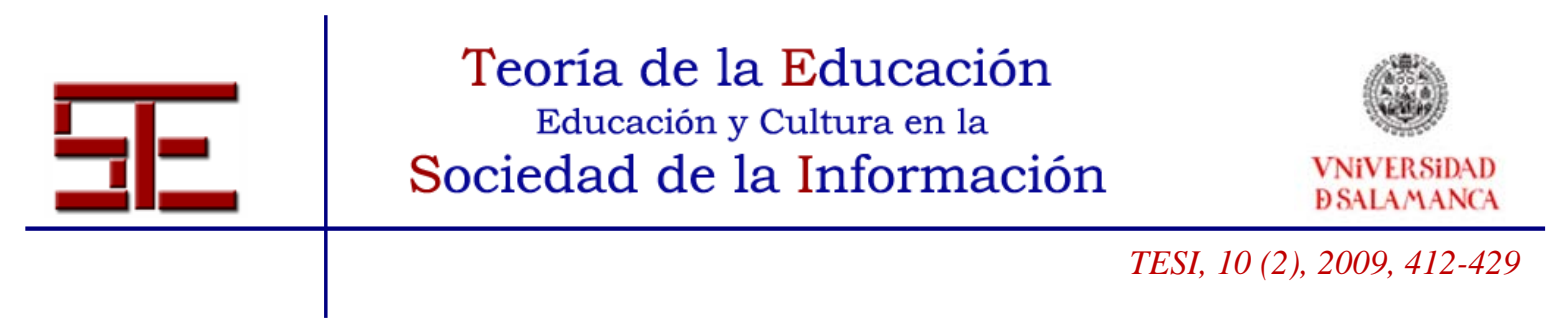

\section{TOWARDS VIRTUAL LEARNING COMMUNITY, LEARNING TO APPROPRIATE THE NEW DIGITAL MEDIA.}

Summary: The results of an analysis of the processes of formation in the educative modality through Internet a distance, considering the possibilities of the virtual environment to facilitate or to prevent the collaboration in network, and therefore the construction of practice communities; the previous thing with the intention to evaluate of that forms those systems of management of the learning in Net (LMS) incorporates elements of virtual design for the methodology that is desired to incorporate in the processes of qualitative and quantitative evaluation, specifically the virtual spaces for the collaborative work and the tools of communication as they are the virtual forums.

Keywords: Communities of Practice, Online Tutoring, virtual learning environments.

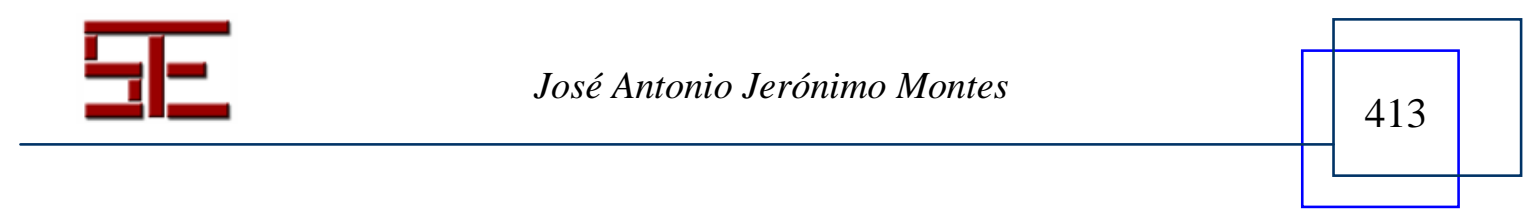




\section{\begin{tabular}{cc} 
Teoría de la Educación \\
Educación y Cultura en la \\
$\begin{array}{c}\text { VNiVERSIDAD } \\
\text { BSALAMANCA }\end{array}$ & Sociedad de la Información \\
\hline TESI, 10 (2), 2009, 412-429 &
\end{tabular}}

\section{HACIA LAS COMUNIDADES VIRTUALES DE APRENDIZAJE, APRENDER PARA APROPIARSE DE LOS NUEVOS MEDIOS DIGITALES.}

José Antonio Jerónimo Montes

jajm@servidor.unam.mx

Universidad Nacional Autónoma de México.

\section{PRESENTACIÓN.}

A partir de cuatro experiencias de formación de tutores para la educación en línea efectuadas, en España y México, se realiza el análisis de la interacción didáctica considerando cuatro distintos entornos virtuales, se consideran elementos metodológicos de la investigación cualitativa; desde la observación participante, la Etnografía virtual (Hine,2000) y el análisis del discurso electrónico. Se realiza un análisis desde el estudio de caso, tomando como foco de análisis los foros de discusión realizados en los cursos de formación de tutores on line, con participantes de distintos contextos, de culturas diversas y a la vez compatibles; donde los une un propósito común, la formación para la realización de actividades para la educación en línea, es decir. Una profesionalización para la práctica educativa.

En el presente documento se rescatan los elementos de presencia social, presencia cognoscitiva y presencia de tutoría (enseñanza) desde la perspectiva de Anderson, Garrison y Rourke (2001). El presente documento tiene como finalidad mostrar la complejidad de la interacción didáctica en línea que se construye a partir del trabajo colaborativo en un entorno virtual que reúne a participantes de distintas latitudes y contextos socioculturales, todos unidos por un mismo lenguaje e intereses compartidos como es en este caso la formación para la educación en Red.

\subsection{El contexto.}

En los inicios del presente siglo XXI estamos comprobando aquello que ha iniciado desde finales del siglo pasado en relación con la incorporación de las Tecnologías de la Comunicación y la Información (TIC) en la vida cotidiana, éstas tecnologías están transformando las vidas de las personas al participar como facilitadores de un mundo interconectado a través de redes digitales, las cuales hacen posible depositar cierta confianza en esas poderosas herramientas de transmisión de información por vía digital. Algunos ejemplos son el uso de la banca electrónica (cajeros electrónicos, cajas de

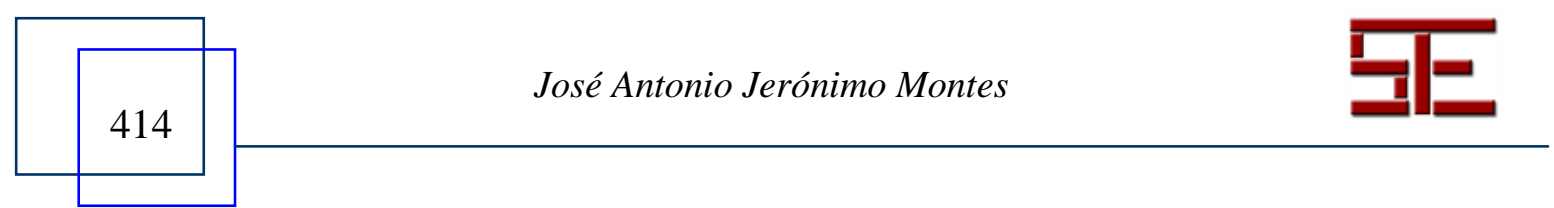




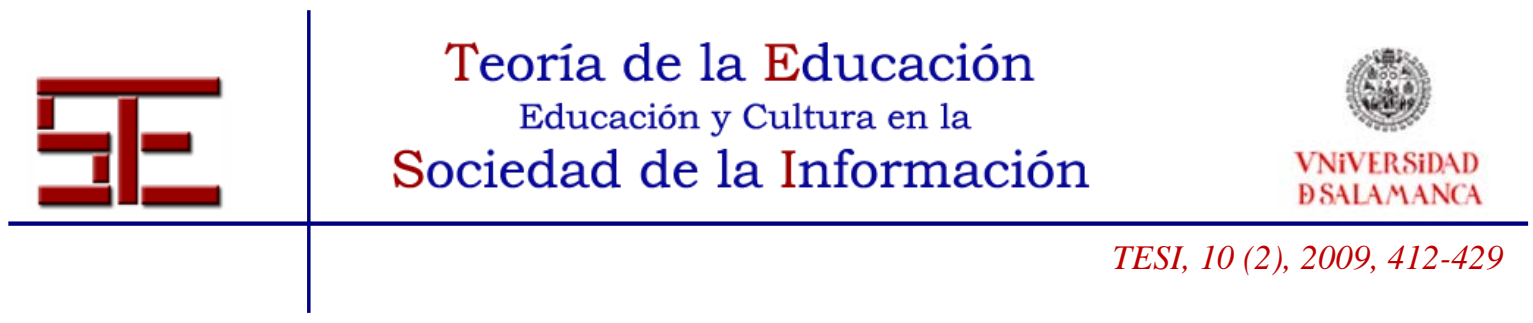

cobro en centros comerciales), servicios de telefonía digital, televisión digital) y ahora con un gran crecimiento las ofertas educativas soportadas por la red Internet en la modalidad educativa a distancia.

Los intercambios soportados por la Internet que se producen entre la gente que no comparte el mismo contexto social y que no proviene del mismo entorno, como aquellos que se presentan en las propuestas de formación a distancia soportadas por la red Internet en el ámbito Iberoamericano, que en muchos casos realizan actividades interactuando con personas de diversas culturas por medio de un código de comunicación que es compartido y negociado el cual en la mayoría de los casos es desconocido durante la conversación; convierten al texto en una representación del lenguaje oral el cual es la forma tradicional del ser humano para entablar relaciones en la vida cotidiana.

Ante lo que parece ser un nuevo entorno de aprendizaje se considera importante proporcionar a estudiantes un ambiente de aprendizaje que los anime a la construcción conjunta de conocimiento apoyándose en la reflexión crítica y la interacción social con otros estudiantes en una comunidad, que al tener como objetivo común los aprendizajes se le puede denominar comunidad de aprendizaje (McConnell, 2000; Palloff Y Pratt, 1999) facilitado por tecnologías modernas.

La investigación realizada en comunidades demuestra que el fuerte sentido de comunidad aumenta no solamente la persistencia de los estudiantes en programas en línea, también enfatiza la necesidad de generar el sentido de "presencia social” en las comunidades virtuales donde se realza la importancia de la interacción a partir del flujo de información que posibilite el trabajo colaborativo, incrementando el sentimiento de cohesión social, lo cual es un elemento que puede ayudar a los aprendizajes en las propuestas educativas en la modalidad en línea. (Dede, 1996; Wellman, 1999) comentan que "sin una sensación de comunidad en las personas que participan, es probable que los participantes ante los retos de un proceso de formación se muestren ansiosos, defensivos y poco dispuestos a tomar los riesgos implicados en la tarea de aprender " (Wegerif, 1998, p. 48). De la literatura que se reporta, uno de los factores importantes relacionados con el sentido de comunidad es la presencia social (Rovai, 2002). Según Garrison y Anderson (2003), la formación de la comunidad requiere un sentido de presencia social entre los participantes.

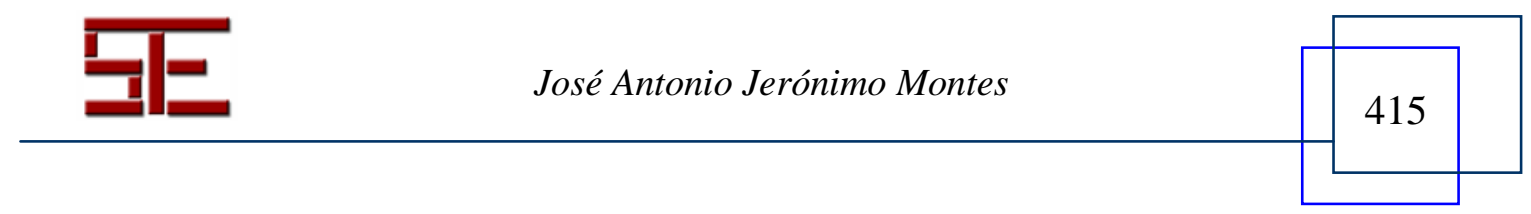




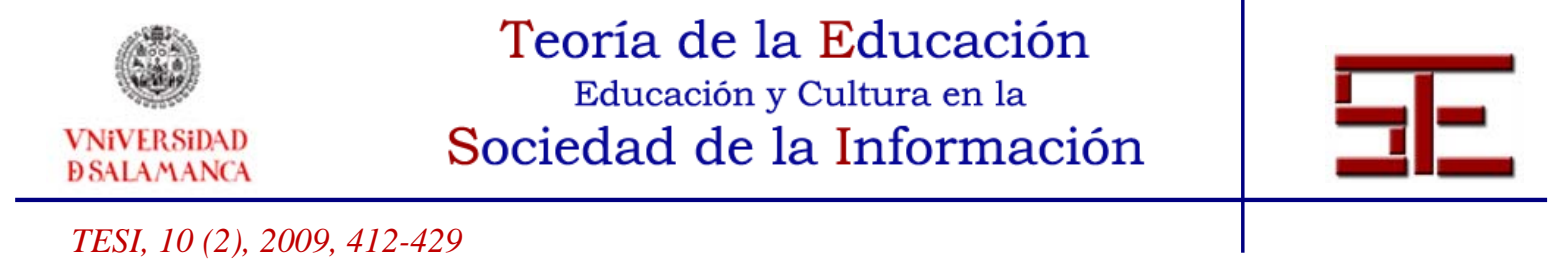

El soporte principal de estas nuevas comunidades es el texto informático que fluye por medio del correo electrónico soportado por la red Internet; a ese tipo de comunicación se le ha denominado Comunicación Mediada por Computador (CMC) Herring (1996). Considerando que el texto se convierte en el medio fundamental para el intercambio no presencial, para la creación de significado que al ser compartido se constituye en el medio esencial para la construcción de comunidades en tanto hay coincidencia de propósitos comunes. De tal forma que para apoyar el pensamiento crítico en las comunidades de aprendizaje que utilizan la CMC Garrison (2000) destaca la importancia de aprender en línea vinculando tres componentes de: 1) la presencia cognoscitiva, 2) una presencia de la enseñanza, y 3) una presencia social.

Usando este marco, la investigación que se comparte concentra su atención en el análisis del discurso electrónico en un enfoque de comunicación, cualitativo y cuantitativo, para entender la presencia social y sus elementos, así como la presencia cognitiva soportadas ambas por el discurso electrónico.

Lo anterior desde el enfoque de la Etnografía virtual; se puede preguntar qué es lo que hace moverse hacia la etnografía virtual, para lo cual se necesita acudir al contexto etnográfico y ubicarlo. Una vía es acudir al contexto de datos tal cual lo hacen los usuarios del mismo; esto es, como un espacio virtual en el que algunos autores como Rheingold (1993) en Lionel (1996) describen como espacios de individuos en la Internet denominados comunidades virtuales. Un etnógrafo virtual hace lo que un etnógrafo común y es tratar al ciberespacio como la realidad etnográfica (Lionel, 1996).

El concepto de comunidad virtual ó de grupo de gente en espacio virtual se vuelve un tópico central en estos inicios de nuevo milenio. Tomando la hipótesis de que tales grupos existen, uno dirige a la etnografía entonces dentro de ellos. La etnología virtual puede construir los estadios comparativos entonces y puede buscar principios subyacentes y la conducta universal (Hine, 2000).

\subsection{Respecto de los cursos que se analizan.}

En el presente trabajo se pretende realizar un análisis de la interacción didáctica que se ha realizado a partir de las actividades académicas desarrolladas en un curso de formación en red en una propuesta de la Universidad de Salamanca España con participantes de distintos contextos geográficos, particularmente de Iberoamérica. Lo anterior reconociendo que la interacción juega un papel fundamental en los procesos de

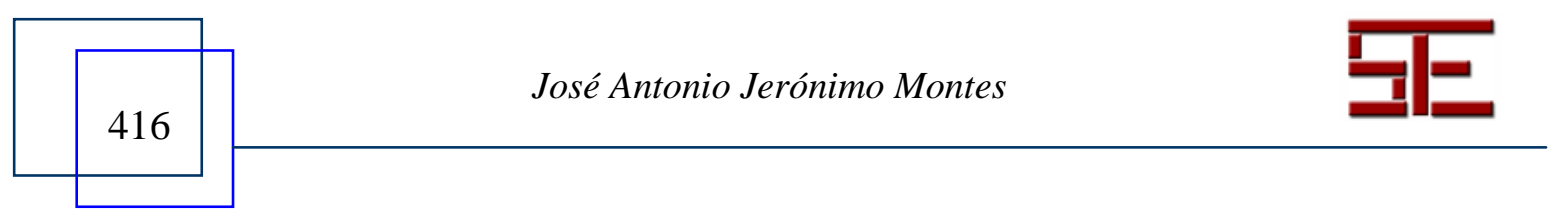




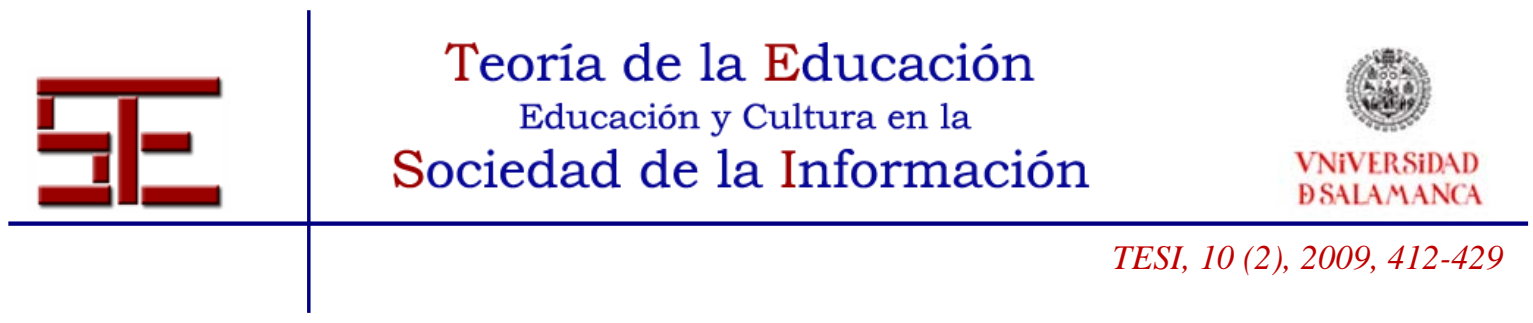

aprendizaje en la modalidad a distancia. El acercamiento se hace desde la postura teórica sociocultural que vincula la interacción con la acción social mediada por instrumentos.

Considerando a la interacción como la interconexión de acciones sociales mediadas que se desarrollan en un determinado escenario; aprender y enseñar en contextos virtuales ha de ser considerados como parte de un mismo proceso interactivo en el cual se produce la construcción situada de conocimiento por parte del aprendiz en función ó como resultado, de un proceso dialógico social en el cual las comunidades de práctica negocian socialmente el significado de los contenidos que se tratan. Así mismo, la cognición como cualquier otra actividad humana está fuertemente influida por condiciones del contexto social en el cual se realiza; es así que toma gran importancia la relación con otras personas en el proyecto de formación en Red que se analiza.

En el presente documento se rescatan los elementos de presencia social, presencia cognoscitiva y presencia de tutoría (enseñaza) desde la perspectiva de Anderson, Garrison y Rourke (2001). El primer elemento en el modelo es el desarrollo de la presencia cognoscitiva, que Garrison et al. (2000) define como "el grado a el cual los participantes en cualquier configuración particular de una comunidad de la investigación son capaces de construir el significado a partir de una comunicación sostenida." El segundo elemento es la presencia de eneseñanza ( tutoria), que incluye el diseño educativo y la conducción de los procesos de aprendizaje como son las secuencias para su logro, proporcionando el docente maestría del tema como experto facilitando un aprendizaje activo.

El tercer elemento es la presencia social, definida como la capacidad de los principiantes de proyectarse social y emocionalmente en una comunidad de indagación. La función de este elemento es apoyar los objetivos cognoscitivos y afectivos del aprendizaje. La presencia social apoya el logro de los objetivos cognoscitivos a partir de la capacidad de cuestionar, de sostener, y de apoyar el pensamiento crítico de los participantes en una comunidad de aprendices. Se apoya el cumplimiento de objetivos afectivos haciendo que en las interacciones del grupo que rescatan y dan continuidad a los aportes de los integrantes se hagan de manera frecuente y recompensando así de una manera intrínseca la pertenencia de la comunidad conduciendo las actividades hacia el aumento en la integración académica, social, e institucional y dando por resultado la terminación creciente de la persistencia en el curso.

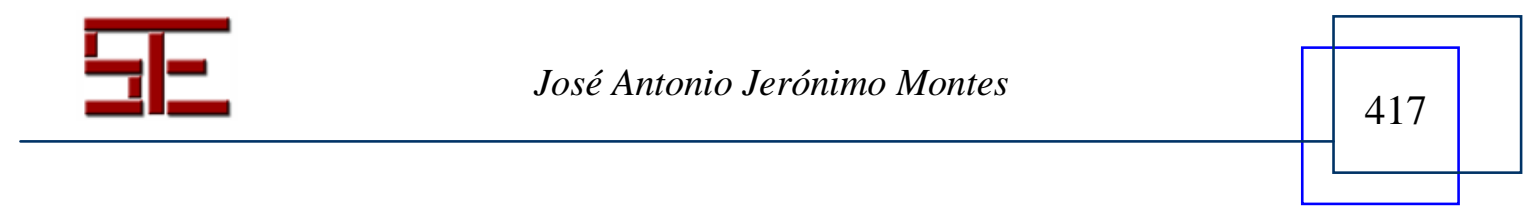




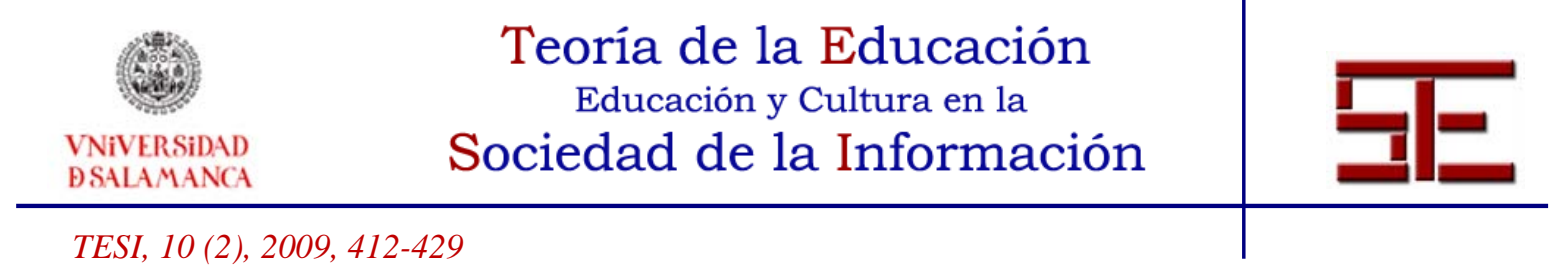

\section{Metodología de Análisis.}

\subsection{Procedimiento.}

La actividad se ha relazado a partir de la observación participante en un curso de especialista en tutoría online que se imparte en la modalidad en línea y que es certificada por una institución educativa española.

Los registros son tomados de un foro de discusión programado como parte de las actividades académicas en un entorno virtual diseñado para el trabajo colaborativo denominado BSCW. Para el acercamiento se ha elegido como unidad de análisis el párrafo por considerarse un elemento consistente para obtener elementos que desde la perspectiva del análisis del discurso aporten elementos respecto de aquello que se construye académicamente a través de la interacción didáctica mediada por el discurso electrónico, que es el medio de comunicación que se soporta a partir de la Comunicación Mediada por Computador (CMC).

De acuerdo con Constantino (2004), podemos diferenciar en los foros el grado o nivel de actividad interactiva que en ellos se desarrolla, más allá del número de participantes y las actitudes individuales que van de una gran exposición al ocultamiento de la propia presencia (lurckers). Es así que, con base en el autor se realiza un análisis desde su propuesta clasificatoria de los modos o estrategias de participación diferenciales encontrados, que son:

a) participación aditiva o relativa al tópico del foro: contiene una opinión, comentario, información sobre el tópico propuesto. No implica “diálogo" con las otras contribuciones.

b) participación interactiva o relativa al flujo discursivo: relativa al flujo discursivo, la contribución tiene un carácter de respuesta a una contribución anterior o se apoya explícitamente en otra para descargar lo propio.

c) participación directiva o tendiente a mantener el flujo discursivo en el tópico: tendiente a fijar o reconducir el flujo discursivo al tópico o a otro tópico o actividad.

Se realiza desde una posición de autoridad o poder relativa al foro, al tópico o a los participantes. También implica animación, evaluación, etc.

d) participación disruptiva o relativa a tópicos diversos: relativa a tópicos diversos de los actuales en proceso en el foro, implica un aparente cambio de

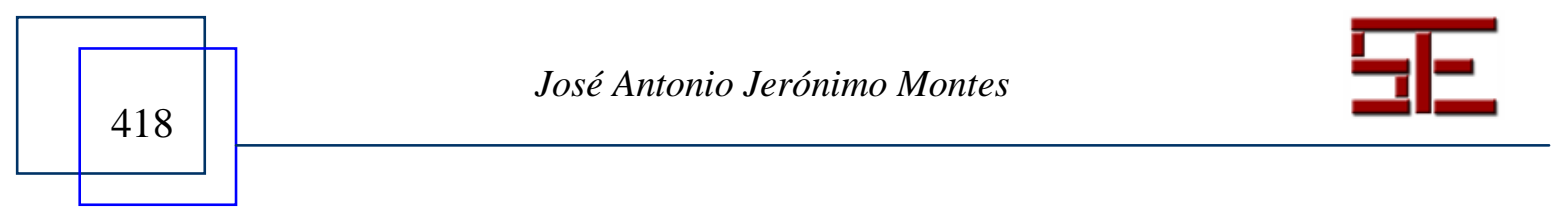




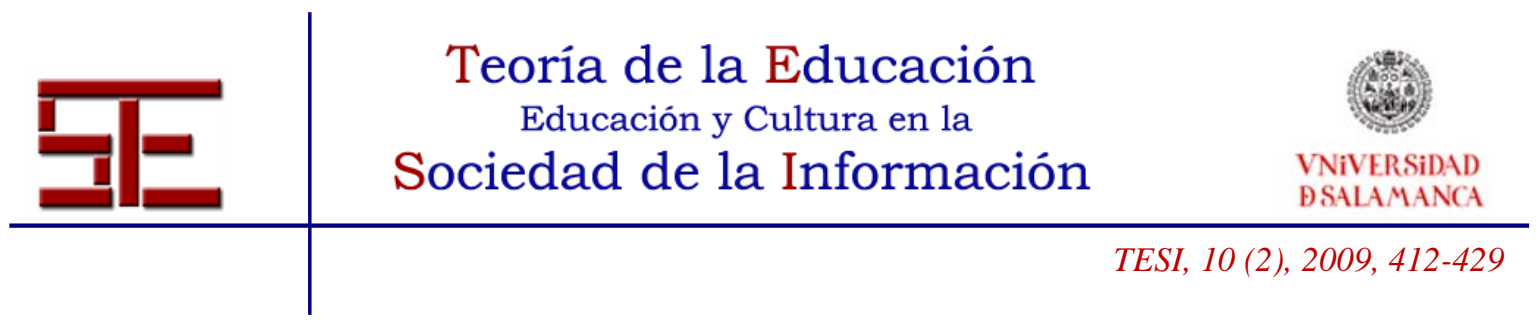

foco con o sin intencionalidad reconocida y con efecto generalmente perturbador cuando no es ignorado.

e) participación anómala o inesperada: a diferencia de la anterior, este tipo de contribución puede ser adecuada al tópico, pero por otras razones se encuentra fuera de contexto.

Así mismo, se desea dar cuenta de los siguientes aspectos:

a) La negociación de significado y co-construcción del conocimiento ante una tarea en particular.

b) Observar como la tarea propuesta nos muestra la construcción social del conocimiento.

El interés está centrado en conocer como se construye el conocimiento en colaboración tomando como base una actividad concreta planificada en un curso en línea. La perspectiva sociocultural es de especial interés ya que le otorga al lenguaje y la interacción un papel preponderante para el desarrollo de las capacidades del ser humano, del aprendizaje con un reconocimiento especial al papel de la cultura y el contexto social del individuo. Es importante mencionar que el ser humano nace sin esa herramienta valiosa para la relación social, que es el lenguaje. Lo adquiere durante su desarrollo como ser natural, así como en su mismo desarrollo como ser social.

$\mathrm{Al}$ aprender el lenguaje, aprende un conjunto de elementos que lo caracterizan como ser social en un contexto particular, se apropia no solo del lenguaje, también de aquellos elementos que le permitirán ser reconocido como poseedor de aquellos elementos construidos por los distintos grupos sociales en los cuales negociará su incorporación, transitando de ritual e ritual de iniciación, de validación y legitimación como miembro de esas comunidades.

Tal es el caso de la formación universitaria donde las comunidades han construido sus propios rituales, y demandan así un conjunto de elementos como parte de la mística denominada profesionalización. Es justo por la necesidad de analizar dichos rituales, que se realiza un acercamiento desde la micro etnografía, ya que es la etnografía una de las fuentes de los estudios del discurso. En este caso desde la Etnografía virtual (Hine, 2001) y la observación participante. Se realiza un análisis desde el estudio de caso, tomando como foco de análisis dos foros de discusión realizados en un curso de formación de tutores online, con participantes de distintos contextos, de culturas

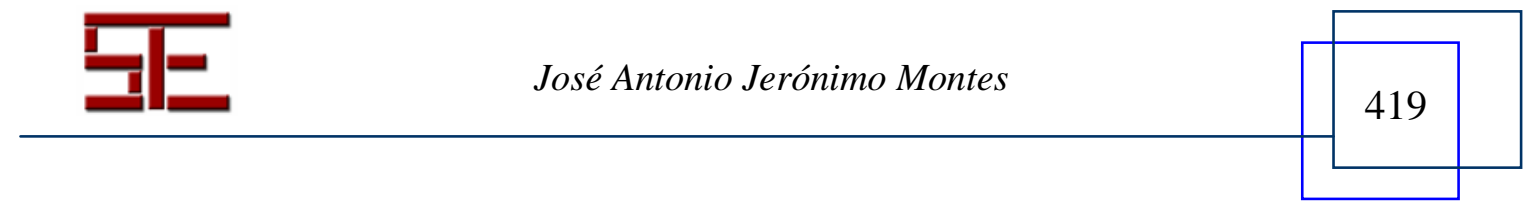




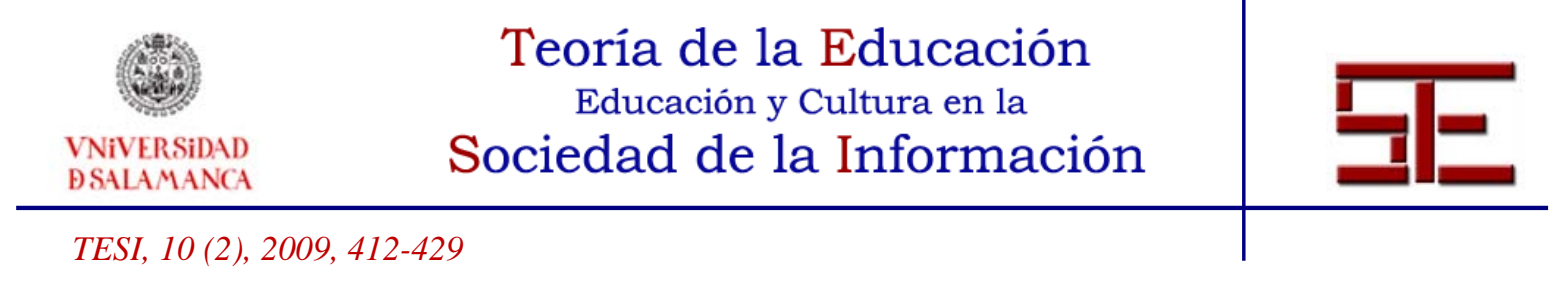

distintas y a la vez compatibles; donde los une un propósito común, la formación para la realización de actividades de tutoría para la Formación en Red, es decir. Una profesionalización para la práctica educativa.

Es de interés hacer un análisis desde la perspectiva sociocultural, particularmente aquella que considera al estudio de la interacción en línea. Han sido recientes los intentos de ir más allá de la mera descripción de los mensajes en los foros de comunicación nasincrónica, para entenderlos como una oportunidad para promover conocimiento y el aprendizaje. En este sentido, destaca el trabajo de Henri (1992), que planteó que la comunicación asincrónica se podría analizar a través de cinco dimensiones: participativa, social, interactiva, cognitiva y metacognitiva. En ese recorrido por analizar la construcción de comunidades en entornos virtuales se han desarrollado intentos nuevos para un acercamiento a la rica interacción que se desarrolla a través de la CMC en la comunicación asíncrona.

Un intento por detectar los patrones de interacción y de esta forma reconocer ¿quiénes hablan y para que lo hacen? Así como ¿cómo lo hacen y en que momento lo realizan? Es siguiendo la "cadena de mensajes" tomando como referencia el "Asunto" del correo electrónico ubicando a la persona que inicia el dialogo y detectando a los demás participantes que con sus contribuciones hacen posible la interacción y la construcción de una comunidad de discurso, además de permitirnos reconocer cuales son los patrones de comunicación e interacción que se generan en estos nuevos entornos de aprendizaje.

A continuación se presenta un análisis de un fragmento de dos foros de discusión:

\section{Caso 1.}

En el caso No. 1 que se presenta, siguiendo la cadena de interacción con base en el asunto, se puede realizar el siguiente diagrama de flujo de participación:
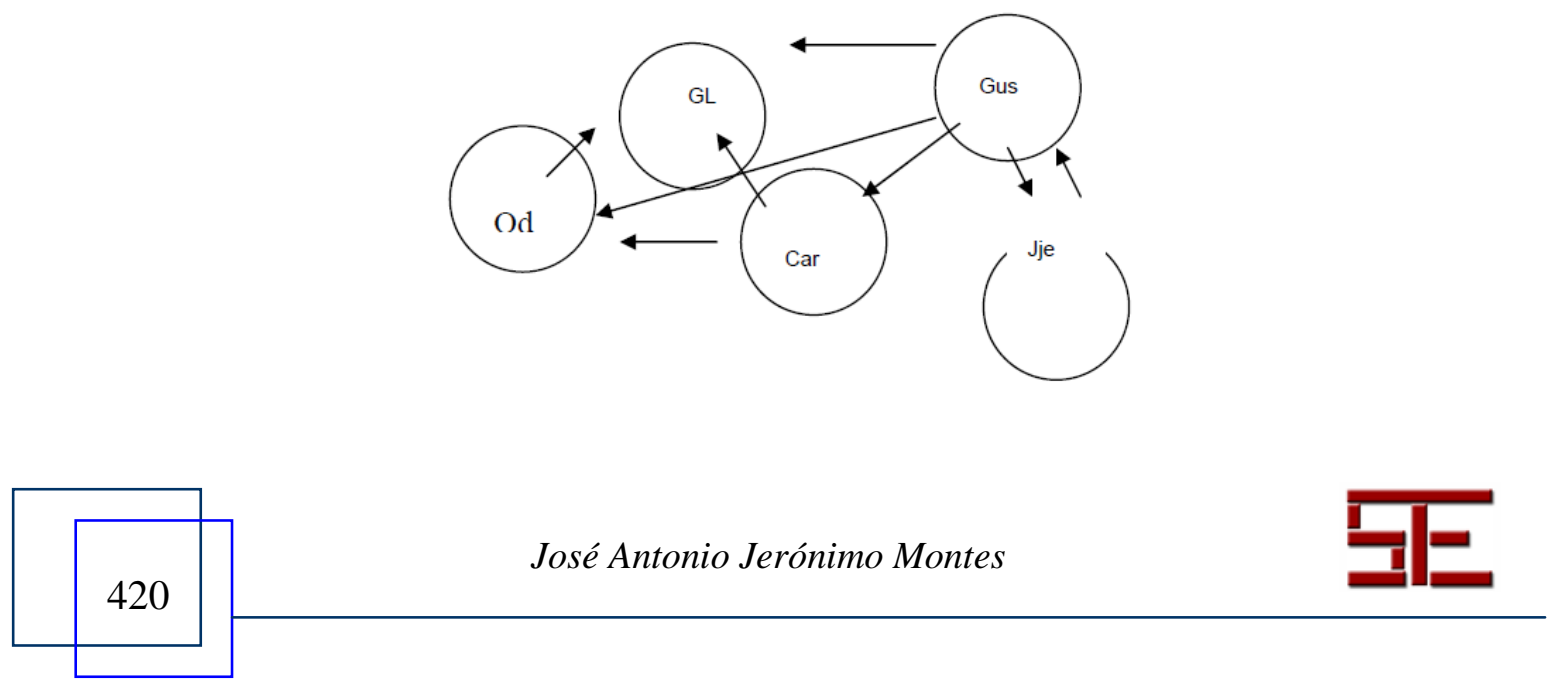


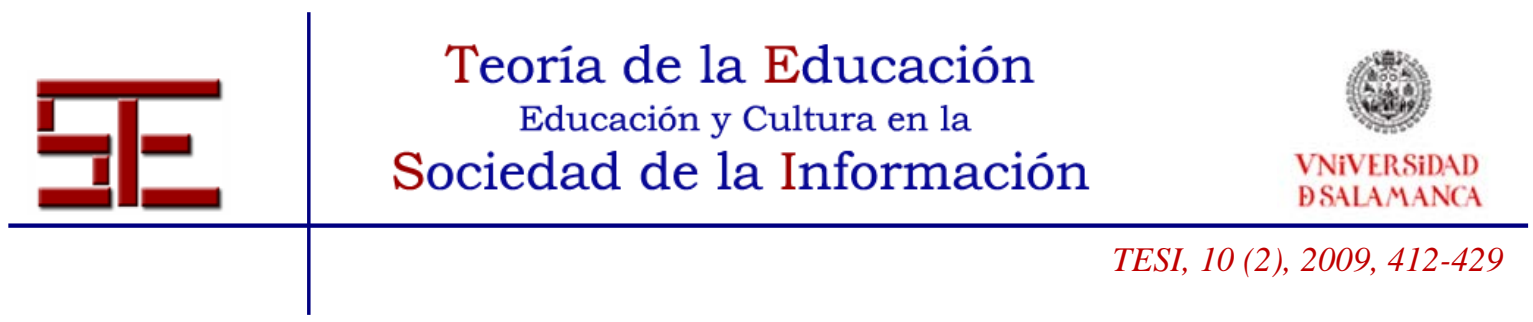

En la cadena de Mensajes que se ha presentado podemos rescatar varios elementos:

a) en el "Asunto" del mensaje la temática que da sentido al dialogo virtual (discurso electrónico) y que lo ubica dentro de un contexto específico ( el texto en contexto) que en este caso es la problemática "Sobre el conocimiento explícito y tácito".

b) La incorporación que hace el sistema de cómputo de la palabra "Re" nos indica que ese mensaje electrónico es producto de una Respuesta a por lo menos una interacción previa: "RE: Sobre el conocimiento ecplícito y tácito”.

Apoyándonos en el asunto y la cadena de interacción se puede notar que la temática abordada a partir de un documento de trabajo propuesto en el programa de formación, ha convocado al menos a tres integrantes quienes de manera explícita atienden al llamado de GL para profundizar en su propuesta.

Se considera importante resaltar que en dicha cadena de interacción aparecen solamente los aprendices del curso y no se da presencia del tutor, quienes construyen un dialogo virtual centrado en la temática afín orientándose y debatiendo tomando como pretexto el contenido del material proporcionado, así como los aportes que desde la experiencia concreta personal y del foro de discusión se rescata por los participantes.

Un hallazgo obtenido de este ejercicio de organización son los patrones de interacción que a diferencia de la educación presencial, no se orientan ó están centrados en el profesor (tutor); en los entornos estudiados la interacción si bien puede ser iniciada por el docente, en momentos posteriores la comunicación se mueve más hacia los estudiantes que participan en el proceso de formación.

A continuación la cadena de interacción completa, tal cual ha quedado registrada en el foro de discusión sobre esta temática en particular que se registra por el Asunto del mensaje:

Caso 1.

Sobre el conocimiento explícito y tácito

El conocimiento explícito puede ser estructurado, almacenado y distribuido. El conocimiento tácito . que forma parte de las experiencias de aprendizaje personales de cada uno de nosotros ¿creen que sería posible de estructurar, almacenar y distribuir?

Graciela

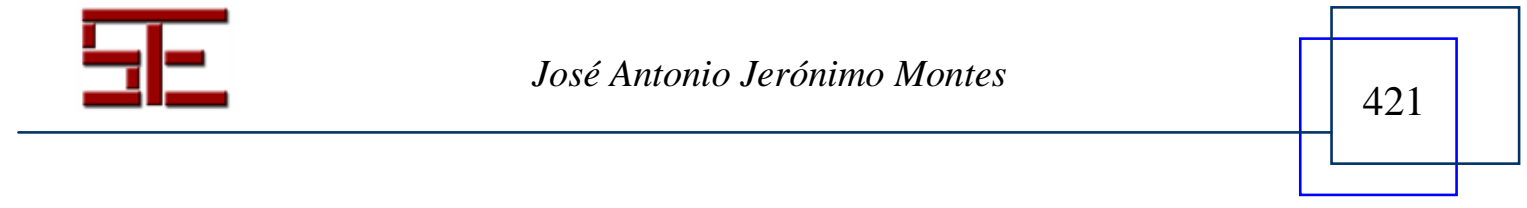




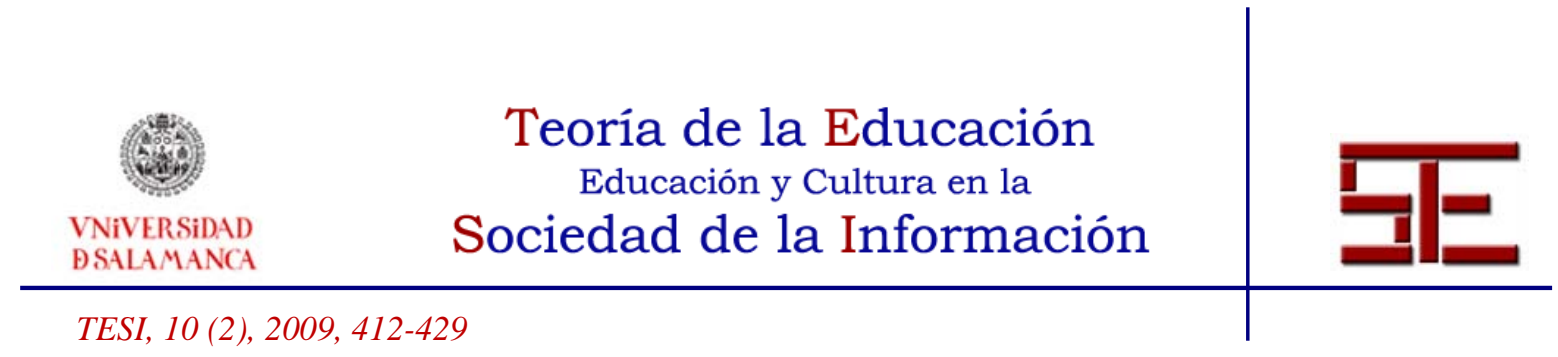

GI 2004-10-14 19:47

RE: Sobre el conocimiento explícito y tácito

Hola Graciela, respondiendo a tu pregunta:

El conocimiento tácito, ¿creen que sería posible de estructurar, almacenar y distribuir?

Creo que según las características del conocimiento tácito: experencial y simultáneo, no puede organizarse mediante las tres acciones anteriores, porque sólo a través de la conversión a conocimiento explícito es posible su organización.

Aunque me queda la duda de si al producirse la interiorización, de conocimiento explícito a conocimiento tácito, como este viene organizado y estructurado, entonces podemos almacenarlo de manera jerarquizada. Si esto es posible entonces mi idea inicial es errónea.

Álvaro

Car 2004-10-14 03:47

\section{RE: Sobre el conocimiento explícito y tácito}

El conocimiento explícito puede ser estructurado, almacenado y distribuido. El conocimiento tácito, que forma parte de las experiencias de aprendizaje personales de cada uno de nosotros ¿creen que sería posible de estructurar, almacenar y distribuir?

Creo que la respuesta es no: Como tal el conocimiento tácito no es susceptible de ser almacenado porque no trata de conceptos fáciles de categorizar, sino más bien tiene que ver con lo que muchas veces se da por supuesto, se aprende "con el roce", no se verbaliza. Sólo cuando entra en la espiral y se trasforma en explícito se puede estructurar, almacenar, distribuir.

A esta pregunta yo añadiría: ¿cómo puede el conocimiento tácito "entrar en acción" en un soporte escrito como el nuestro? ¿Puede pese a todo generarse exteriorización en estos medios? Me imagino que la respuesta es sí (y me parece asombroso, lo confieso).

Olga D

Od 2004-10-14 03:54

\section{RE: Sobre el conocimiento explícito y tácito}

Querida Olga, respondiendo a tu pregunta:

¿Cómo puede el conocimiento tácito "entrar en acción" en un soporte escrito como el nuestro?

¿Puede pese a todo generarse exteriorización en estos medios?

La expresión y difusión del conocimiento tácito se realiza a través, de analogías y ejemplos prácticos.

Entonces tu y yo podemos estar manteniendo una conversación sobre "la educación a los niños inmigrantes en la escuela", por ejemplo, y al final de la conversación tu o yo producimos una serie de conocimientos establecidos y reglamentados que difundimos a través de una conferencia, por ejemplo.

¿No lo crees así?

Álvaro

Car2004-10-14 04:02

Tomando como base la propuesta de análisis de la interacción de los foros de discusión online de Constantino (2004) tenemos: La participación de Gl como una participación directiva, retomamos un fragmento:

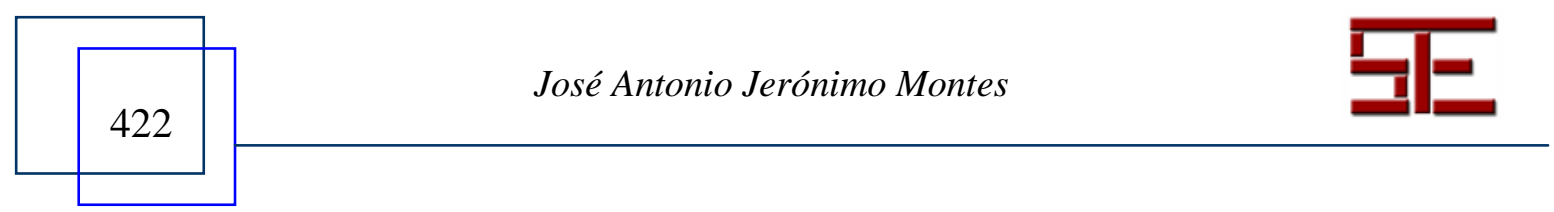




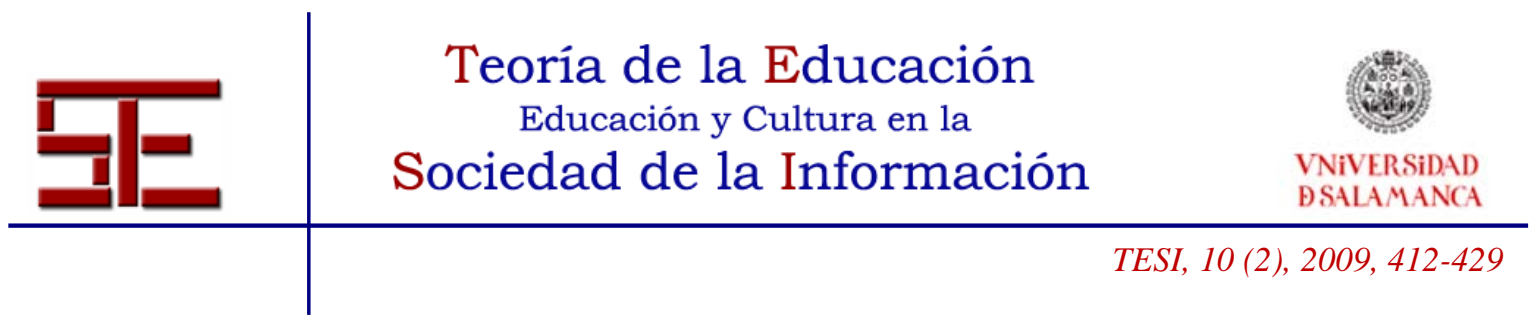

"El conocimiento explícito puede ser estructurado, almacenado y distribuido. El conocimiento tácito que forma parte de las experiencias de aprendizaje personales de cada uno de nosotros ¿creen que sería posible de estructurar, almacenar y distribuir?”

En dicho mensaje, se realiza un aporte que si bien no está relacionado con una participación previa, inicia un nuevo tópico en torno a la temática general abriendo un espacio invitando a construir una cadena de interacción, reconduce el flujo discursivo a otro, como es el que analizamos.

Respecto de la presencia cognitiva, GL hace una reflexión sobre los materiales y retoma dicho contenido para promover el debate a partir de un cuestionamiento particular.

Considerando la presencia social, en dicha participación se apoya el logro de los objetivos cognoscitivos cuestionando y sosteniendo el pensamiento crítico, promoviendo el debate en torno a la temática que orienta el documento de trabajo.

En el siguiente mensaje, donde Car da respuesta a GL se puede dar cuenta de un mensaje del tipo Participación Interactiva como se muestra a continuación:

Creo que según las características del conocimiento tácito: experencial y simultáneo, no puede organizarse mediante las tres acciones anteriores, porque sólo a través de la conversión a conocimiento explícito es posible su organización. Aunque me queda la duda de si al producirse la interiorización, de conocimiento explícito a conocimiento tácito, como este viene organizado y estructurado, entonces podemos almacenarlo de manera jerarquizada. Si esto es posible entonces mi idea inicial es errónea.

En la participación de Od a Gl se da cuenta de una participación directiva ya que aporta elementos suficientes para fijar el flujo discursivo. Además de contribuir a la presencia cognoscitiva, particularmente por el proceso metacognitivo que da cuenta de un proceso de reflexión que se comparte en la comunidad del discurso, así mismo, se detecta presencia social ya que aporta elementos motivadores y de cuestionamiento que animan al debate tal como se aprecia a continuación:

Creo que la respuesta es no: Como tal el conocimiento tácito no es susceptible de ser almacenado porque no trata de conceptos fáciles de categorizar, sino más bien tiene que ver con lo que muchas veces se da por supuesto, se aprende "con el roce", no se verbaliza. Sólo cuando entra en la espiral y se trasforma en explícito se puede

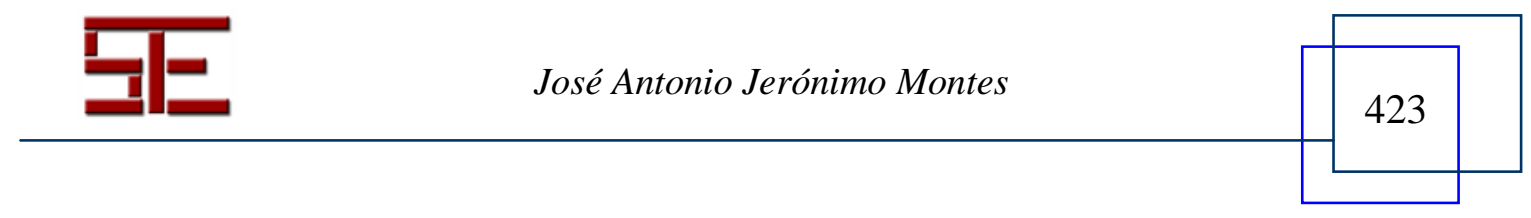




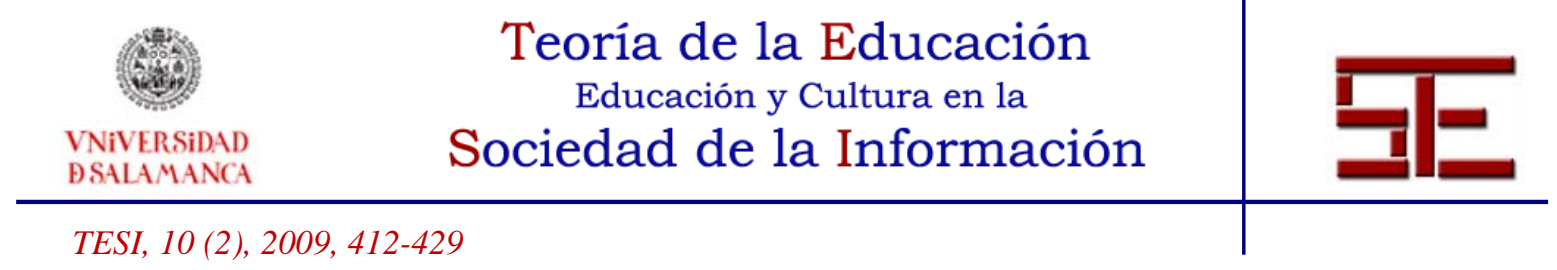

estructurar, almacenar, distribuir. A esta pregunta yo añadiría: ¿cómo puede el conocimiento tácito "entrar en acción" en un soporte escrito como el nuestro? ¿Puede pese a todo generarse exteriorización en estos medios? Me imagino que la respuesta es sí (y me parece asombroso, lo confieso).

Respecto de la Presencia de Tutoría, en la cadena general de mensajes-interacción del foro, el tutor "Gus" ha decidido abrir un nuevo tópico denominado "Respuesta breve sobre "tácito" e "implícito", donde rescata elementos del espacio abierto por Gl del cual se ha dado cuenta líneas arriba. En ese aporte donde el tutor orienta y resalta algunos elementos del material propuesto, se aprecia que solamente uno de los participantes (Jje) genera una línea de interacción como se puede observar, donde el grupo considera que el tópico ha sido abordado de manera suficiente.

\section{Respuesta breve sobre "tácito" e "implícito"}

José Antonio, iexcelentes aportes!

No habría gran diferencia entre ambos términos, salvo que cuando hablamos de "teorías implícitas" son referidas al individuo y con un alcance más amplio, en contextos diversos; el conocimiento tácito es más contextual y socialmente dependiente.

Por ejemplo, en este curso ToL, vuestra comunidad ha recorrido un breve pero intenso camino y tienen ya una "historia" para mí desconocida en cuanto me inserto ahora y no estoy desde el principio (no es tan así, porque un tutor debe pedir, si están disponibles, "coordenadas" contextuales antes de actuar). Pero más allá de lo que me han referido y lo que ustedes me cuenten, hay elementos tácitos que desconozco totalmente; eventos, actitudes y conocimientos que los diferencian (no olviden que hay un grupo B).

Gus 2004-10-14 14:53

RE: Respuesta breve sobre "tácito" e "implícito"

Saludos estimados Gustavo y amigos.

Te agradezco los comentarios, me han aclarado bastante, se me hacía dificil ver lo contrario, me agrada saber que puedo rescatar la propia historia para avanzar en nuevos aprendizajes.

Ahora, como lo he comentado y veo que se tiene previsto. Me interesa mucho develar aquellos elementos que participan como agentes en lo implícito ( como agentes secretos) en las comunidades naturales y en aquellas artificiales ( creadas con intervención ó por la mano del hombre como en las empresas).

Algo similar a un acto terapéutico para a través del análisis del discurso electrónico "tomar" aquellos aspectos que me permitan intervenir como tutor en las propuestas educativas on line, para de ahí, como lo promueve la estrategia de investigación cualitativa desde el análisis del discurso; darle voz a aquellos que no la han tenido ( los actores como son los aprendices) para generar propuestas de Formación en Red que retomen la propia experiencia acumulada y concentrada como conocimiento cultural de la comunidad de práctica, y transitar hacia un conocimiento explícito que permita hacer "tangible" la producción intelectual y de esa forma avanzar en aquello que nos preocupa y nos ocupa en este curso, generar propuestas de formación en red que reconozcan las voces de los participantes.

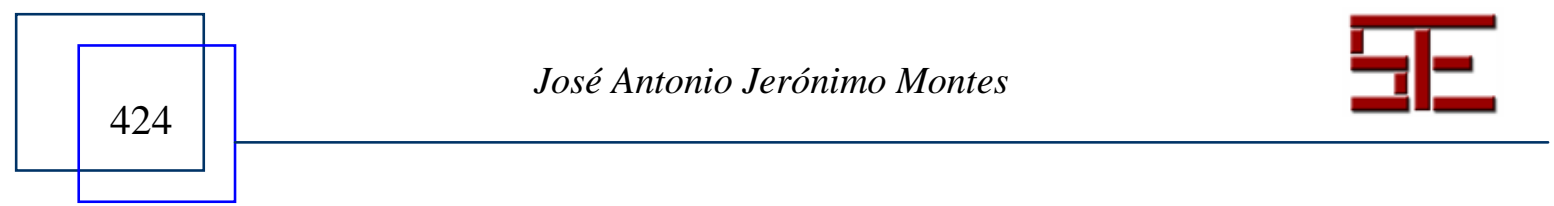




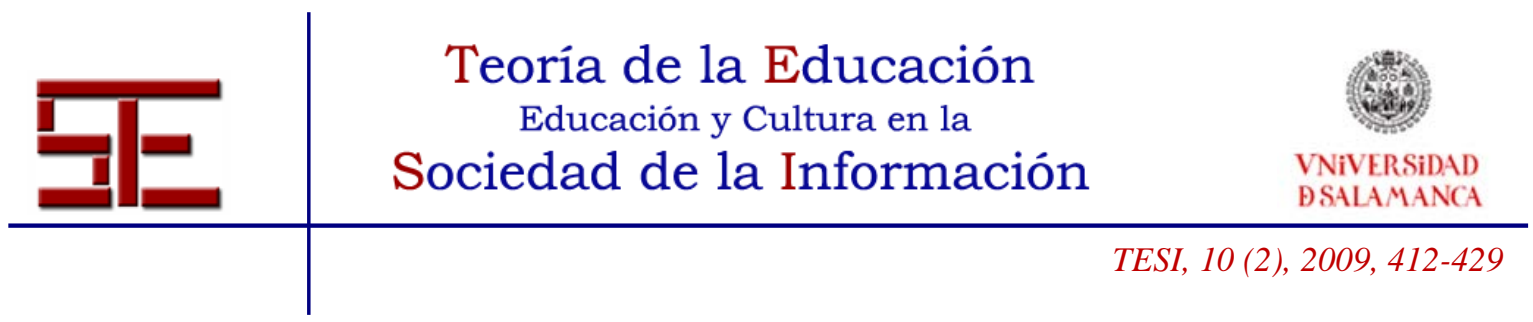

Aprovecho para comentar que me agrada saber que la perspectiva del análisis del discurso electrónico que retoma en este bloque de contenidos. Me gustaría saber desde donde se hará esa aproximación.

Modelos teóricos y experiencias en investigación educativa, particularmente lo referido a las comunidades de práctica.

Bien, un cordial saludo y un fuerte abrazo.

Jje 2004-10-14 23:41

Como se puede notar, el análisis de la interactividad, además de implicar una definición de actuación de los participantes como acción dirigida y orientada a los otros, supone contemplar de manera integrada los aspectos discursivos: lo que dicen los participantes y cómo lo dicen; y no discursivos: lo que hacen los participantes y cómo lo hacen- de la actividad conjunta.

En la cadena de interacción del Caso 1 que se ha presentado, tomando en cuenta el concepto de comunidad, podemos observar que ésta tiene una historia, que es también una comunidad "de recuerdos", definida en parte por su pasado y la memoria del pasado.

Toma sentido lo aportado por McMillan y Chavis (1986) que definen a la comunidad como "una sensación de pertenencia en los miembros, una sensación en que los miembros importen a uno otro y al grupo, y una fe compartida en que las necesidades de los miembros sean resueltas con su comisión de hacerlo juntos".

Así mismo, lo aportado por Westheimer y Kahne (1993) quienes definen el sentido de comunidad como el resultado de la interacción y deliberación de la gente reunida por intereses similares y metas comunes, o como un ambiente en el cual los participantes obran recíprocamente de una manera cohesiva, reflejándose continuamente sobre el trabajo del grupo con un amplio respeto a lo construido y aportado por los miembros individuales reconociendo las diferencias del grupo (Graves, 1992). Estas definiciones sugieren los elementos más esenciales de comunidad: interdependencia mutua entre miembros, sentido de pertenecer, de interconexión, confianza, interactividad, expectativas comunes, valores compartidos y historias de las metas, y de la interrelación entre los miembros.

\section{Conclusión.}

El presente documento tiene como finalidad mostrar la complejidad de la interacción didáctica en línea que se construye a partir del trabajo colaborativo en un entorno virtual

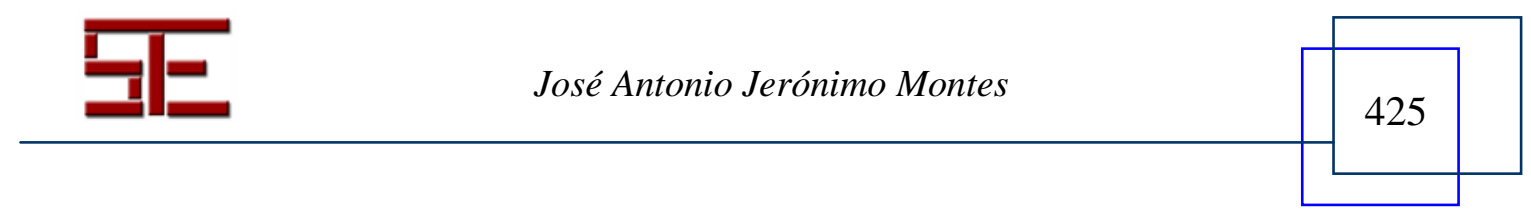




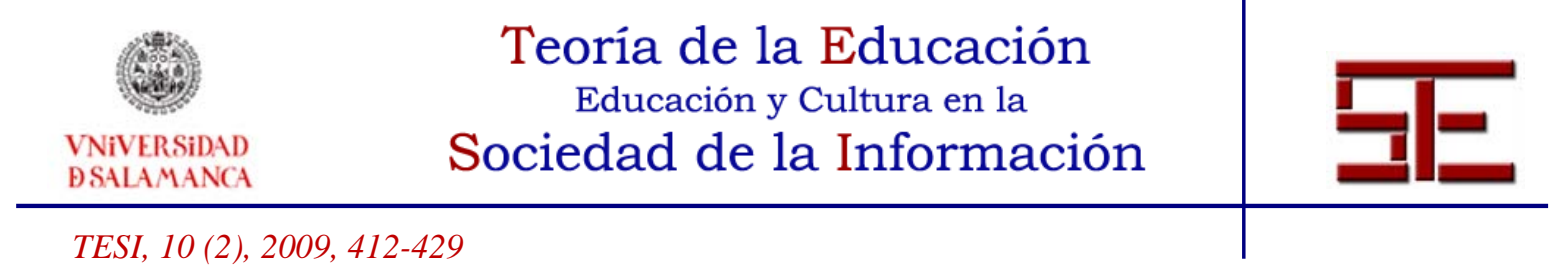

que reúne a participantes de distintas latitudes y contextos socioculturales, todos unidos por un mismo lenguaje e intereses compartidos como es en este caso la formación para la tutoría en red.

En las comunicaciones se da cuenta de los procesos de negociación de significados que si bien no son compartidos en un inicio y que constituyen elementos de poder simbólico como es la información particular de la profesión ó del área en la cual se enmarca la propuesta de formación, durante la interacción en red se gestan un conjunto de elementos que pueden ser caracterizados como un ritual educativo, los cuales al ser vertidos durante una actividad educativa hacen posible la negociación de significados y la apropiación de ellos por los distintos integrantes que están interesados en formar parte de dicha comunidad, lo cual contribuye a la constitución de un sentido de comunidad; de una comunidad del discurso donde es el lenguaje escrito la herramienta de mediación que contribuye a la construcción de una comunidad de aprendizaje.

Es en este sentido que toma relevancia la necesidad de formar académicos en esta nueva vertiente educativa que es el análisis del discurso virtual, que contribuya a la construcción de una presencia de tutoría basada en el discurso electrónico, aportando elementos a la vez para los procesos de planificación y evaluación en Red reconociendo que estamos ante un nuevo paradigma educativo.

\section{Bibliografía.}

Aviv, R., Erlich, Z., Ravid, G. y Geva, A. (2003). Network Analysis of Knowledge Construction in Asynchronous Learning Networks. JALN, septiembre, 7 (3)

Brown, R. (2001). The Process of Community-Building in Distance Learning. JALN, 5 (2), Septiembre.

Calhoun, C. (1991). Indirect Relationships and Imagined Communities: Large-Scale Social Integration and the Transformation of Everyday Life. In P. Bourdieu y J. S. COLEMEN (Eds.): Social Theory for a Changing Society. Boulder, CO: Westview Press. pp. 95-120

Cerulo, k. A. (1997). Reframing Social Concepts for a Brave New (Virtual) World. Sociological Inquiry, 67 (1), 48-58.

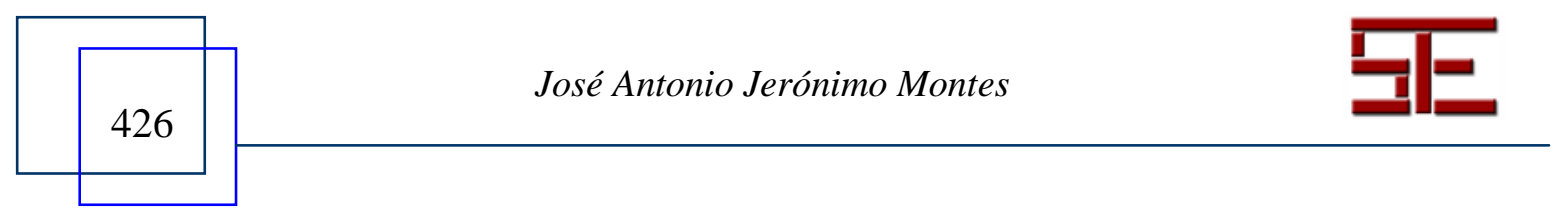




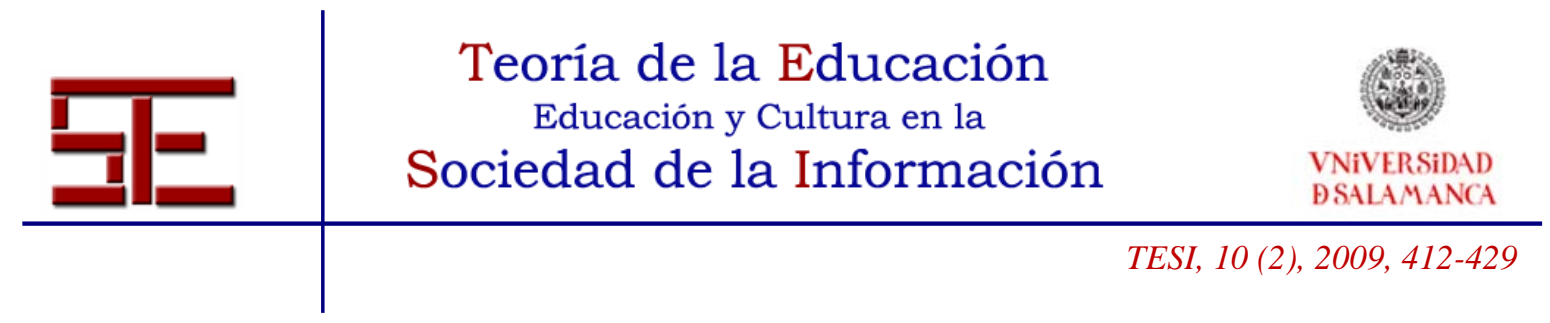

CICOGNANI (1997). Design speech acts. "How to do things with words" in virtual communities.[url] http://www.arch.usyd.edu.au/ anna/papers/caadf97.html Consultado en Marzo de 2003.

Constantino, G. (2004). Documento de trabajo en el curso Tutor On line, Univesidad de Salamanca.

Crichton, S. y Kinash, S. (2003). Virtual Ethnography: Interactive Interviewing Online as Method. Canadian Journal of Learning and Technology, 29 (2)

CRYSTAL (2002). El Lenguaje e Internet. Cambridge University Press.

Dawn, B. K. (1999). Gender Differences in Asynchronous Learning in Higher Education: Learning Styles, Participation Barriers and Communication Patterns. JALN, $3(1)$.

Dubrovsky, V., Kiesler, S. y Sethna, B. (1991). The equalization phenomenon: Status effects in computer-mediated and face-to-face decision making groups. Human Computer Interaction, 6, 119-146.

Foertsch, J. (1998). "The Impact of Electronic Networks on Scholarly Communication: Avenues for Research." Discourse Proceses. 19.

Gilbert, N. y Mulkay, M. (1984). Opening Pandora's Box: A Sociological Analysis of Scientists Discourse. Cambridge University Press: Cambridge.

Henri, F. (1992). Computer conferencing and content analysis. In KAYE, A. (Ed.) Collaborative learning through computer conferencing: The Najaden papers. Berlin: Springer-Verlag (pp. 117-136).

Herring (1996). Computer-Mediated Discourse Analysis. The electronic Journal of Comunication. 6 (3).

Hine, C. (2000). Virtual Ethnography. Sage, Londres.

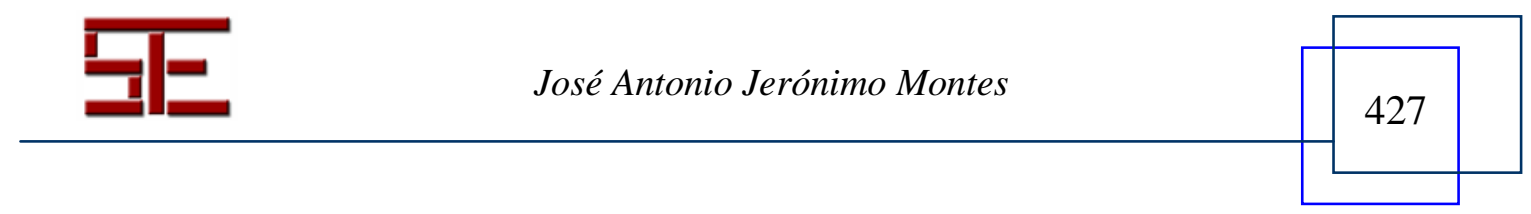




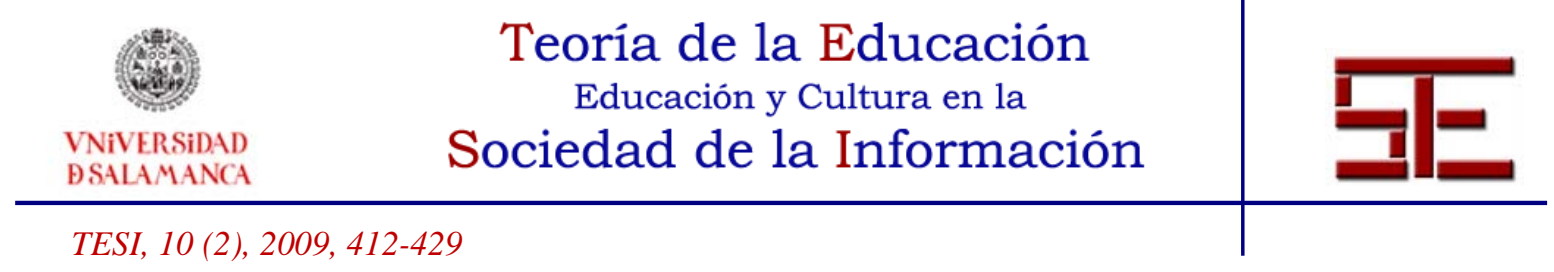

Jackson, G. (1998). Electronic Discourse: Toward a Dialogic Framework for Scholarly Collaboration. [url] http://www.intertwining.org/collaboratory/papers/NixJackson/edisc.html. Consultado en febrero de 2003.

Jonsson, E. (1998). Electronic discourse on speech and writing on the internet. Lulea University of Technology. [url] http:

//www.ludd.luth.se/users/jonsson/Dessay/ElectronicDiscourse.html. Consultado en diciembre de 2002.

Kelle, U. (1997). Theory Building in Qualitative Research and Computer Programs for the Management of Textual Data. Sociological Research Online, vol. 2, no. 2, [url] http://www.socresonline.org.uk/socresonline/2/2/1.html> Consultado en Mayo de 2003.

Kiesler, S.; Siegel, J. y Mcguire, T. W. (1984). Social psychological aspects of computer-mediated communication. American Psychologist, 39.

Marcelo, C. (2002). Aprender con otros en la red. Investigando las evidencias. Congreso VirtualEduca 2002. Disponible en: [url] http://www.webformacion.net Consultado enero de 2003.

Miller, D. y Slater, S. (2000). The Internet an Ethnographic Approach. (Oxford: Berg) Genre Analysis. Cambridge, New York.

Murray, T. (1991) .An Overview of Computer Mediated Communications Transción de una conferencia en la University de Victoria \&, Simon Fraser University. [url] http://eies.njit.edu/\%7Eturoff/Papers/victalk.htm. Consultado en Octubre de 2003.

Nobilia, B. (1998). The Computer-Mediated Communication, A New Way of Understanding The Language. International Conference: 25-27 Bristol, Reino Unido.

Nystrand, M. (1982). What Writers Know: The Language, Process, and Structure of Written Discourse. (New York: Academic, 1982), p. 17.

Paccagnella, L. (1997). Getting the Seats of Your Pants Dirty: Strategies for Ethnographic Research on Virtual Communities. JCMC, 3 (1) June.

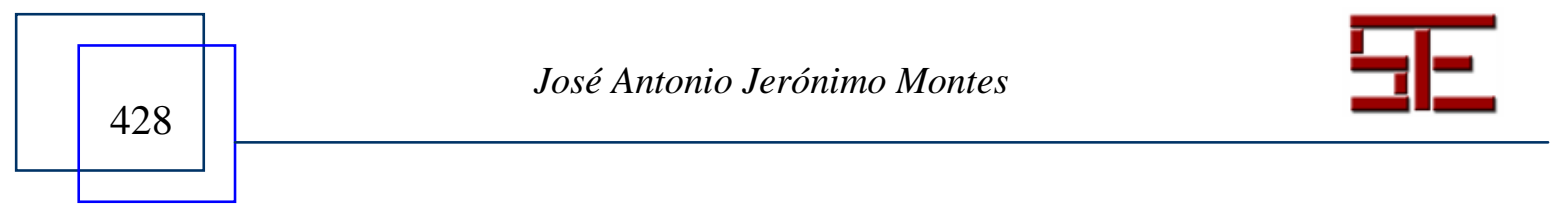




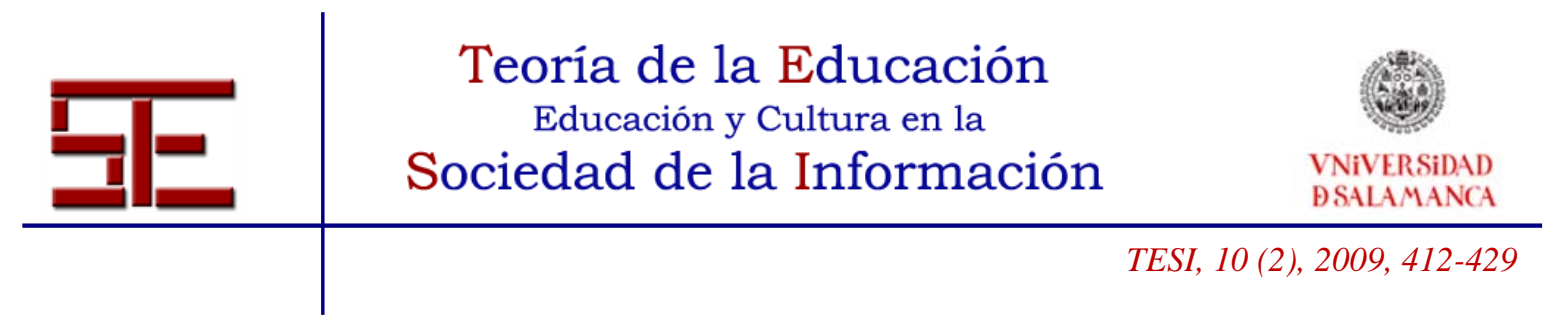

Parks, M.R. y Floyd, K. (1996). Making friends in cyberspace. Journal of ComputerMediated Communication [On-line], 1 (4).

http://www.usc.edu/dept/annenberg/vol1/issue4/parks.html

Rourke, I., Anderson, T., Garrison, A. y Archer, W. (2001). Assessing Social Presence In Asynchronous Text-based Computer Conferencing. Journal of Distance Education/Revue de l'enseignement à distance (2001)

Sébastien, G. ( 2003). Analyse automatique de conversations textuelles synchrones d'apprenants pour la détermination de comportements sociaux. Sciences et Technologies de l'Information et de la Communication pour l'Éducation et la Formation. Vol.10

Steven R. Thomsen, Joseph D. Straubhaar, Drew M. Bolyard (?). Ethnomethodology and the study of online communities: exploring the cyber streets Information Research, 4 (1) Julio.

Van Dijk, T. (2001). El discurso como interacción Social. Gedisa: España.

Westheimer, J. y Kahne, J. (2003). Reconnecting Education to Democracy: Democratic Dialogues. Phi Delta Kappan. 84 (1). September. Introduction to special issue on Democracy and Education.

Para citar la presente editorial puede utilizar la siguiente referencia:

Jerónimo Montes, J. A. (2009). Hacia las comunidades virtuales de aprendizaje, aprender para apropiarse de los nuevos medios digitales, en Ortega Sánchez, I. y Ferrás Sexto, C. (Coord.) Alfabetización Tecnológica y desarrollo regional. Revista Electrónica Teoría de la Educación: Educación y Cultura en la Sociedad de la Información. Vol. 10, no 2. Universidad de Salamanca, pp. 412-429 [Fecha de consulta: $\mathrm{dd} / \mathrm{mm} /$ aaaa].

http://campus.usal.es/ revistas_trabajo/index.php/revistatesi/article/view/7523/7556

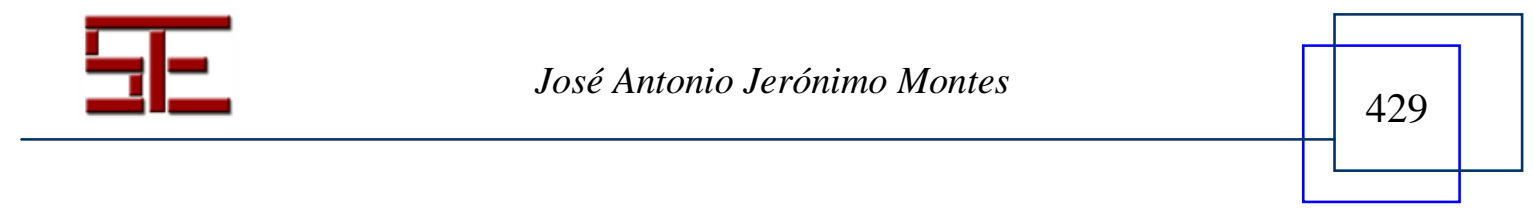

